\title{
Public universities and regional growth - insights from the University of California \\ Martin Kenney e David C. Mowery (Eds.)
}

Stanford, CA: Stanford University Press, 2014, 247p.

Ana Maria Nunes Gimenez*

Maria Beatriz Machado Bonacelli**

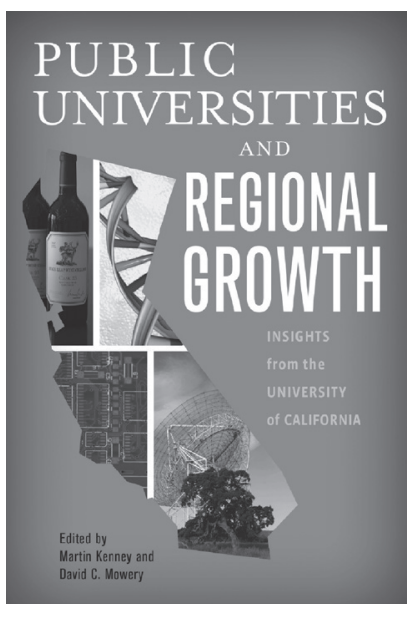

Public universities and regional growth - insights from the University of California, editado por Martin Kenney e David C. Mowery, discute a movimentação de pessoas, recursos e tecnologia entre universidade e indústria, tema em debate na academia há décadas, pois pauta a preocupação de uma maior integração entre esses dois atores centrais nos sistemas de inovação e de transferência de conhecimento. No centro desta discussão estão o papel das instituiçõos relevantes (universidades, institutos de pesquisa, empresas e seus laboratórios de $P \& D)$ e a construção e consolidação de mecanismos que permitam e estimulem a interação (e a manutenção desta) entre esses atores.

O foco da análise é a evolução das relações da universidade com a indústria em seis campi do Sistema da Universidade da Califórnia. O sistema público da Califórnia foi fundado em 1869, com a criação do campus de Berkeley, voltado à pesquisa e ao ensino nas áreas das ciências humanas e naturais. ${ }^{1}$ Os estudos $\mathrm{e}$

* Universidade Estadual de Campinas (Unicamp), Campinas (SP), Brasil. E-mail: agimenez@ige.unicamp.br

** Universidade Estadual de Campinas (Unicamp), Campinas (SP), Brasil. E-mail: bia@ige.unicamp.br

1 O Sistema da Universidade da Califórnia é composto por dez campi, cinco centros médicos e três laboratórios nacionais, oferecendo 150 cursos de graduação, 600 programas de pós-graduação e 20.000 cursos de extensão. Conta com 238.700 alunos, 198.300 funcionários, 61 ganhadores do Prêmio Nobel, entre outros. Os campi são os seguintes: UC Berkeley, UC Davis, UC Irvine, UCLA, UC Merced, UC Riverside, UC San Diego, UC San Francisco, UC Santa Barbara e UC Santa Cruz (http://www. universityofcalifornia.edu/uc-system). 
análises que compõem o livro vão desde o campo da ciência da computação até a produção de vinhos.

Partindo do princípio de que a economia baseia-se cada vez mais no conhecimento, a universidade, especialmente a de pesquisa, passa a ser vista como instituição central no apoio à inovação tanto pela realização de atividades de pesquisa, quanto pela formação de estudantes, devido à sua capacidade de colocá-los em contato com a investigação científica de fronteira, fornecendo um mecanismo poderoso para transferências de conhecimento e de tecnologia.

O Bayh-Dole Act tem sido considerado um importante instrumento de indução e favorecimento das relações entre universidade e empresa, questão analisada em diversos estudos. A obra reconhece que houve realmente um aumento substancial no patenteamento realizado pela universidade no período que sucedeu à edição da lei norte-americana, sendo que muitas dessas patentes foram licenciadas a empresas privadas. Diante disso, a referida lei tem sido apontada como uma iniciativa de sucesso, influenciando a criação de políticas similares em diversos países. No entanto, Kenney e Mowery deixam claro que nem sempre esses mecanismos (patenteamento e licenciamento) têm sido considerados essenciais, muito menos imprescindíveis, para a construção dos relacionamentos com o setor produtivo.

Os autores mencionam que muitos estudos empíricos sobre as relações entre a pesquisa universitária e a indústria utilizam essencialmente dados relativos a patentes e licenciamentos, com o fluxo de conhecimentos se deslocando da universidade para a indústria, num movimento unidirecional, o que exteriorizaria o "modelo linear" simplista de inovação. No entanto, essa perspectiva de análise não consegue alcançar as interações que ocorrem a partir de outros canais não exclusivamente ligados ao patenteamento, cujo caráter é muito mais interativo.

Os diferentes tipos de interações que ocorreram ao longo dos anos, nos diversos campi da Universidade da Califórnia, evidenciam que os impactos da universidade no seu entorno dependem de um conjunto de fatores, muitos deles sem relação direta com o modelo fechado do Bayh-Dole Act. Esse é um importante aspecto diferenciador da obra em relação às similares, pois se preocupa em traçar a evolução dos diferentes tipos de relaçôes, sem focar exclusivamente nos mecanismos formais, e também porque abrange diferentes campos de pesquisa, enriquecendo o entendimento sobre as efetivas contribuições das universidades de pesquisa para a sociedade em geral, mas especialmente para os ecossistemas aos quais pertencem.

Constatou-se, por exemplo, que a Universidade de Berkeley desempenhou importante papel no crescimento da indústria de semicondutores no Vale do Silício. 
Além disso, dados indicam que as Universidades de Berkeley, de Los Angeles e de Santa Bárbara, em determinados momentos, orientaram suas agendas de pesquisa para a solução de problemas práticos da indústria, o que possibilitou intensas atividades de transferência de tecnologia para start-ups. No entanto, a pesquisa também constatou que uma significativa contribuição dessas universidades, ao longo dos últimos 40 anos, foi a formação e qualificação de milhares de especialistas em microeletrônica e semicondutores (engenheiros, mestres e doutores) que, em grande parte, passaram a trabalhar nessas áreas em empresas da Califórnia.

Os autores constataram que quando clusters de alta tecnologia se consolidam perto de universidades, como é o caso do cluster de nano-instrumentação de Santa Bárbara, parece ocorrer um movimento constante de indivíduos da academia para as empresas e vice e versa, o que enriquece o relacionamento e mesmo o crescimento da região. Análises sobre a relação da universidade com a indústria de comunicação sem fio de San Diego sugerem que as potenciais contribuiçôes de universidades de pesquisa para o crescimento regional são muito mais amplas e incluem mais elementos que simplesmente a presença de pesquisadores renomados ou a transferência de tecnologias patenteadas. Ao longo dos anos, a universidade tem treinado e fornecido mão de obra qualificada para a indústria, assim como diversos profissionais da indústria têm interagido com a universidade. Observou-se, por exemplo, que o cluster "sem fio" regional de San Diego tem auxiliado a universidade no seu papel de formar e treinar engenheiros e cientistas, especialmente devido às pesquisas colaborativas e às trocas de experiências.

Ao estudar a relação entre o setor de vinhos do Napa Valley e o Departamento de Viticultura e Enologia da Universidade da Califórnia (UC Davis), constatou-se que muitos dos conhecimentos iniciais, que fluíram do meio acadêmico para a indústria, foram tácitos, especialmente transmitidos a partir da interação, cooperação e aprendizado mútuos. Historicamente, as interaçōes entre a universidade e a indústria de vinhos têm ocorrido por intermédio da pesquisa e extensão agrícola ${ }^{2}$ (estabelecida nos EUA no final do século XIX) e não pelo modelo Bayh-Dole de interação. Ao longo dos anos, a indústria de vinhos tem realizado contribuições financeiras significativas para a universidade, embora as ferramentas de pesquisa desenvolvidas não tenham sido patenteadas, nem licenciadas, mas fornecidas gratuitamente para a indústria. $\mathrm{O}$ estudo deixa claro, portanto, que nem sempre os contratos formais,

2 Nos EUA o grande impulso para a expansão das universidades se deu com a aprovação do Morrill Act (Lei Morrill), de 1862, que instituiu a doação de terras, por parte da União, para que os estados desenvolvessem universidades e faculdades voltadas à tecnologia e agricultura. Um dos resultados foi o surgimento de diversos programas de extensão, especialmente a agrícola (C. Kerr. Os usos da Universidade. 15. ed. Brasília: UNB, 2005). 
o patenteamento e o licenciamento foram os caminhos escolhidos para solidificar as interaçôes. A importância da UC Davis para o Napa Valley reflete-se na elevada percentagem de diplomados da universidade trabalhando como enólogos no Vale. Em 2012, por exemplo, uma pesquisa revelou que, dos 395 enólogos atuantes na região, 231 eram egressos da UC Davis.

$\mathrm{O}$ estudo contrasta com outros do gênero pelo fato de o foco ser uma universidade pública líder em pesquisa, enquanto trabalhos anteriores focavam em instituições de ensino superior, como o MIT e Stanford. Isso é importante porque, em 2009, conforme dados do National Science Board de 2012, as universidades públicas de pesquisa dos Estados Unidos realizaram aproximadamente $70 \%$ da pesquisa acadêmica, usaram cerca de $60 \%$ dos fundos federais para P\&D e foram responsáveis por 34\% dos bacharelados e mais de $50 \%$ dos doutorados concedidos no mesmo ano.

Em resumo, pode-se, portanto, apontar que:

- as formas como a pesquisa acadêmica pode contribuir para a inovação industrial variam conforme o setor industrial e o campo científico, sendo que essas particularidades devem ser levadas em consideração; assim, não existe um modelo único aplicável a todos os casos;

- a gestão das relaçôes entre universidades e empresas deve ser flexibilizada para ser capaz de acomodar diferentes abordagens para a gestão da propriedade intelectual, licenciamento e inovação;

- muitas vezes, dados sobre patentes ou licenciamentos não conseguem identificar a existência de outras formas e canais de transferência de conhecimento e interação, como, por exemplo, o fluxo pessoas e ideias da universidade para a indústria e vice e versa;

- nem sempre os contratos formais, patenteamento e licenciamento são os caminhos escolhidos para interações entre universidades e empresas, sendo por esse motivo que a ênfase nos mecanismos formais de cooperação reforça, muitas vezes, o modelo linear e unidirecional de inovação;

- $\quad$ o estudo evidenciou que a ausência de patentes não impede a criação de novas empresas;

- as políticas devem privilegiar relações interativas como uma forma de alcançar e maximizar benefícios mútuos, para não desencorajar outros tipos de relacionamentos benéficos que podem ocorrer entre a indústria e a academia. 